\title{
Rapid Maxillary Expansion Effects on the Upper Airway Dimensions and Function in Growing Patients: An Umbrella Review
}

\author{
Silvia Gianoni-Capenakas, DDS, MSc ${ }^{1}$; Karla Carpio Horta, DDS, MSc PhD² ; Carlos Flores-Mir DDS, MSc, DSc., FRCD(c) ${ }^{1}$; Manuel \\ O. Lagravère, DDS, MSc, Ph.D., FRCD (c) ${ }^{1}$; Camila Pacheco-Pereira, DDS, MBA, MSc ${ }^{1,3}$
}

${ }^{1}$ School of Dentistry, Faculty of Medicine and Dentistry, University of Alberta, Canada; ${ }^{2}$ School of Dentistry of Ribeirao Preto, University of Sao Paulo, Brazil; ${ }^{3}$ University of Texas Health Science at San Antonio, San Antonio, Texas

\begin{abstract}
Objective: Because numerous published systematic reviews have assessed the effect of rapid maxillary expansion (RME) over upper airway dimensional changes, it is important to map and summarize their conclusions. In addition, the accepted methods used to evaluate the upper airway across the different systematic reviews will be outlined and areas of strengths and weaknesses on the topic identified.

Methods: Systematic reviews in which RME treatment outcomes as related to upper airway dimensional changes or breathing function in children and adolescents were included in this umbrella systematic review. Studies that investigated upper airway changes using three-dimensional imaging (cone beam computed tomography, computed tomography, magnetic resonance imaging), acoustic rhinometry, rhinomanometry, and polysomnography correlated with RME effects were included. Studies on expansion using palatal anchorage with miniscrews and surgically assisted maxillary expansions were excluded, as well as studies including syndromic patients. Results: Sixty-six studies were found from the database searches. After managing duplicates, 33 studies were assessed based on the titles and abstracts, but only 16 reviews were considered for the next assessment phase (full text). From then, only 10 systematic reviews were finally included in this umbrella review.

Conclusions: A significant amount of research has been published linking RME changes to increases in nasal respiratory capability, nasal volume, and linear transverse enlargement. However, methodologic inconsistencies and disagreements between the included studies (especially on the oropharyngeal dimensional changes after RME) lead to significant uncertainties about the consistency of the effect of RME changes, especially on the oropharynx region dimensions. It is not clear that the upper airway dimensional changes necessarily imply an improvement in actual breathing function.
\end{abstract}

Keywords: sleep apnea, maxillary expansion, upper airway obstruction, review

Citation: Gianoni-Capenakas S, Horta KC, Flores-Mir C, Lagravère MO, Pacheco-Pereira C. Rapid maxillary expansion effects on the upper airway dimensions and function in growing patients: An umbrella review. J Dent Sleep Med. 2020;7(4)

\section{INTRODUCTION}

The upper airway is part of the respiratory system and comprises the nasal cavity and surrounding sinuses, oral cavity, and pharynx. ${ }^{1}$ Upper airway function includes air warming and humidification, defense against infection, protection from food aspiration, ventilation, swallowing, and speech. $^{1}$ Upper airway volume variation after orthodontic treatment has been heavily studied, but still has shown several inconsistencies because of differences in methodologic approaches and a large number of orthodontic/orthopedic appliances tested.

Maxillary expansion is used to correct maxillary deficiencies commonly related to posterior crossbites and crowding. ${ }^{1}$ The most common technique used in mixed dentition is rapid maxillary expansion (RME) with a toothanchor expander (Hyrax and Haas appliances). ${ }^{1}$ After maxillary expansion, the separation of the maxillary halves occurs followed by the separation of the nasal walls and lowering of the middle part of the palate vault. ${ }^{2}$ Additional reported changes related to the maxillary expansion are stretching of the tensor palatine muscles and improving the drainage of the eustachian tubes, reducing otitis media and conductive hearing loss. ${ }^{2,3}$ In addition to those changes, nasal permeability may increase and nasal air resistance may reduce. ${ }^{2,4,5}$ RME has been associated with changes in upper airway dimensions; however, the extent of these changes, the long-term effectiveness, and the relationship between airway dimensional changes and breathing capacity is still controversial, especially those changes related to the oropharynx portion. ${ }^{6-10}$

Different methods for evaluating the upper airway dimensions and functions are available, although each has its advantages and drawbacks. ${ }^{10}$ Cone beam computed tomography (CBCT) allows the rendering of the upper airway volume in a three-dimensional view, permitting the assessment of certain upper airway volumetric, linear, and angular measurements. Although it usually has a higher ionizing radiation dose than cephalometric radiographs, CBCT is overall more accurate than two-dimensional imaging. ${ }^{11}$ For ear, nose, and throat specialists, the primary professionals who assess the upper airway, acoustic rhinometry (AR) is the first tool of choice, as it gathers volumetric and cross-sectional area data from reflected signals. This may be followed by direct visualization via nasoendoscopy and PSG.

There are several types of literature reviews. An umbrella review is justified in cases when there is 
contradictory evidence coming from multiple previously published reviews. An umbrella review focuses on highlighting the strengths and weaknesses of previous reviews that address interventions and their results for a specific condition. In this sense, because numerous published systematic reviews have assessed the effect of RME over upper airway dimensional changes, it is important to map and summarize their conclusions. In addition, it is helpful to outline the methods used to evaluate the upper airway across the different systematic reviews and to identify strengths and weaknesses on the topic to guide future research and to make the readership aware of how those findings shape clinical approaches.

\section{METHODS}

The Preferred Reporting Items for Systematic Reviews and Meta-Analysis (PRISMA) was used as a guideline for the methodologic approach of this study. ${ }^{12}$

\section{Eligibility Criteria}

Systematic reviews in which RME treatment outcomes as related to upper airway dimensional changes or breathing function in children and adolescents were included in this umbrella systematic review. Studies that included healthy patients or patients with sleep-breathing disorders were listed. Studies that investigated upper airway changes using three-dimensional imaging (CBCT, CT, MRI), AR, rhinomanometry, and polysomnography (PSG) correlated to RME effects were included. Because the focus of this study is RME, studies on expansion using palatal anchorage with miniscrews surgically assisted maxillary expansions were excluded, as well as studies including patients exhibiting syndromic symptoms. No limitations of time or language were imposed.

\section{Information Sources}

To identify systematic reviews related to our inclusion criteria, the following databases were searched: Cochrane, EMBASE, MEDLINE, and PubMed. Additionally, a hand search was performed. The search was carried out in April 2018, and an update was performed in April 2019. The search results were exported to Rayyan Software (Qatar Computing Research Institute, Doha, Qatar ${ }^{13}$ in which the duplicates were excluded (Figure 1).

\section{Search}

The final search strategy displayed in Appendix 1 shows the search strategy and truncations used for each database.

\section{Selection of Sources of Evidence, Data Charting Process and Data Items}

Two reviewers (SGC and $\mathrm{KCH}$ ) independently evaluated the studies by screening the titles and abstracts, using a web-based citation management program (RefWorks, ProQuest LLC; and Rayyan, Qatar Computing Research Institute, Doha, Qatar). The articles were screened in full text in the second phase by the same two reviewers and, in cases of disagreement, a third reviewer was consulted (CPP). The data were extracted by the first examiner (SGC) and each article was charted. The key features were listed as authors, country, year, type of appliance, area of the airway evaluated, modalities of evaluation (e.g., volume, minimum cross-sectional area, apnea/hypopnea index (AHI), oxygen saturation), type of test to assess airway changes, and main results (Table 1). In addition, the data included in each systematic review are summarized in Table 2.

\section{Critical Appraisal of Individual Sources of Evidence}

The assessment of the methodologic quality of each systematic review was executed using the AMSTAR 2 tool. This tool focuses on critical and noncritical weaknesses. ${ }^{14}$ It can be ranked as high quality, moderate quality, low quality, and critically low quality. ${ }^{14}$

\section{Summary Measures and Synthesis of Results}

The studies were evaluated regarding volumetric and minimal cross-sectional area changes in the upper airway (nasal cavity, nasopharynx, and oropharynx), respiratory function (AHI), and oxygen saturation. Also, the type of examinations (CBCT, AR, PSG) was assessed, as well as the type of RME and long-term effects of these variables.

The studies were grouped according to the analyzed airway section (nasal cavity, nasopharynx, oropharynx, and hypopharynx) and described in terms of the effects of RME in the upper airway.

\section{Risk of Bias Across Studies}

The risk of bias (RoB) across studies was evaluated, comparing the differences across studies such as type of RME, type of examinations, and type of outcome. In addition, a comparison of the RoB among individual reviews was considered. To date there is no published validated RoB assessment tool across included systematic reviews in cases of umbrella reviews. 


\section{RESULTS}

\section{Selection and Characteristics of Sources of Evidence}

Sixty-six studies were identified from the database searches. After managing duplicates, 33 studies were assessed based on the titles and abstracts; 17 of them were excluded. The remaining 16 reviews were screened by assessing their full text. The references of the included studies were also screened for possible new inclusions. In total, 10 systematic reviews were included in this umbrella review.

The characteristics associated with the target group, number of articles included, main findings, databases searched, type of appliance, portion of airway analyzed, type of evaluation and tests or examinations used to evaluate upper airway dimensions and function are summarized in Table 1.

\section{Critical Appraisal Within Sources of Evidence}

The AMSTAR 2 tool results shown in Table 2 are divided into 16 questions and the results displayed into 4 possible categories: high, moderate, low, and critically low quality of evidence. Only one systematic review was ranked with high quality of evidence, ${ }^{2}$ one received a moderate rating ${ }^{10}$; three were rated low ${ }^{9,15,16}$; and five received a critically low rating. ${ }^{7,17-20}$ The lack of a protocol registration was the most common critical domain across the studies. Although it is not possible to affirm the lack of registration or if the information was just not reported in the studies. Also, the lack of information about the study design and RoB assessment of individual studies was also noted in most of the systematic reviews.

\section{Results of Individual Sources of Evidence: General Information}

Lee et al. ${ }^{20}$ analyzed the pharyngeal changes after RME or protraction, but the current study focused only on the results related to RME alone. Di Carlo et al. evaluated the upper airway changes comparing CBCT protocols. ${ }^{15}$ Vale et al. evaluated the available studies examining patients with obstructive sleep apnea (OSA) treated with RME for posterior crossbites and analyzing the AHI rates after the RME treatment. ${ }^{18}$ Ortu et al. evaluated changes in oropharyngeal airway volume and minimal cross-sectional area (MCA) after the use of RME. ${ }^{19}$ Huynh et al. and Camacho et al. evaluated upper airway changes after RME in children in whom OSA was diagnosed. ${ }^{7,9}$ Gordon et al. evaluated nasal dimensional changes through AR after RME treatment. ${ }^{16}$ Buck et al. described the volumetric changes in the upper airway after RME. ${ }^{2}$

\section{Upper Airway Function}

Huynh et al., Camacho et al., and Vale et al. evaluated the efficacy of RME in pediatric patients in whom OSA was diagnosed..$^{7,9,18}$ Their principal findings were a decrease of AHI after RME, and improved mean oxygen saturation and higher oxygen saturation after RME. Camacho et al. stated that RME could be a primary treatment option for children with small tonsils or the second option in patients in whom adenotonsillectomy failed and OSA persisted thereafter, in children with the constricted maxilla. ${ }^{9}$ Nonetheless, according to Camacho et al., the patients with residual OSA after adenotonsillectomy and RME treatment could have considered multiple oropharyngeal sites of collapsibility (epiglottis, supraepiglottis, and tongue base sites). ${ }^{9}$ The reduction in the obstruction could be a secondary factor associated with post-RME treatment such as an increase in nasal cavity size and consequently improvement in nasal flow; better tongue position after maxillary width expansion; and a stimulus for normal positioning of the mandible after the maxillary teeth repositioning. ${ }^{9}$

An immediate overall decrease of $70 \%$ in the AHI was found, with a reduction from a mean of $8.9 \pm 7 / \mathrm{h}$ to $2.7 \pm$ $3.3 / \mathrm{h}$ after the treatment with RME; aside from two studies, the other 15 showed at least $50 \%$ reduction in $\mathrm{AHI}$ after the RME. ${ }^{9}$ According to Vale et al. the mean decrease for AHI was 3.24 at a $95 \%$ confidence interval $[0.34-6.15] .{ }^{18}$ A more significant reduction of the AHI levels was seen in children with small tonsils or no tonsils. ${ }^{9}$

Regarding oxygen saturation, studies reported an improvement between $0.4 \%$ to $5.7 \%$ in the mean oxygen saturation and a 9\% improvement of lowest oxygen saturation. ${ }^{9}$ Nasal flow increase was also reported $(P<0.05) .{ }^{10}$ Although all the aforementioned results seem consistent, one study emphasized the possibility of some of the changes being related to normal growth and spontaneous remission of OSA. ${ }^{9}$ Huynh et al. reported a high heterogeneity $\left(\mathrm{I}^{2}=98.4 \%, P<0.001\right)$, as did Vale et al. $\left(\mathrm{I}^{2}=98.02 \%, P<0.0001\right.$ for AHI improvement, and $\mathrm{I}^{2}=95.53 \% \quad P<0.0001$ for AHI normalization). ${ }^{7,18}$ According to Vale et al., this is a likely finding because a small number of studies included belonged to a few research author groups. ${ }^{18}$ Although RME can positively influence the breathing capacity of patients with OSA, RME treatment is an auxiliary method ${ }^{18}$ and should be used only when orthodontically indicated. ${ }^{21}$

\section{Upper Airway Dimensional Changes}

Alyessary et al. showed that most of the results indicated an increase in the anterior nasal cavity area, from pretreatment to posttreatment $(11.7 \%)$, postexpansion to postretention (22.2\%), and pre-expansion to postretention $(35.7 \%) .{ }^{17}$ Similar results were found in the middle and posterior nasal cavity areas (10\% and $15 \%$, respectively). ${ }^{17}$ 
Nasal width increase was found in several studies and its volume was reported to have increased dimensions after RME treatment. ${ }^{15,22,23}$ An increase in the nasal volume $(11.3 \%)$ was reported..$^{17}$ Lee et al. reported changes in the nasal passage airway volume $(P=0.004) .{ }^{20}$ However, no changes were seen in the lower airway and the airway below the palatal plane $(P>0.05)$ in the same study. ${ }^{20}$ Gordon et al. reported an increase in the nasal volume and MCA; one study demonstrated MCA increase after RME in two groups, one before the pubertal growing peak and the other after the pubertal growing peak. ${ }^{16}$ However, a higher decrease in the MCA was seen after the retention phase in the group after the pubertal growing peak. ${ }^{16}$ Buck et al. $^{2}$ found that overall total airway volume increased; when evaluated via AR, studies showed a statistically significant increase in nasal volume $(P<0.001)$ with an increase from $2 \mathrm{~mm}^{3}$ to $6 \mathrm{~mm}^{3}$. An increase in volume of the velopharynx, nasopharynx, oropharynx and hypopharynx was found; however, there was a decrease in the remaining volume gain after the retention when compared to the volume results right after the expansion in the nasopharynx and oropharynx. ${ }^{2}$

Regarding the oropharynx, one study found differences in the oropharyngeal volume; however, those changes were not statistically significant. Other studies showed a statistically significant increase in oropharyngeal volume after RME. ${ }^{22,24}$ Conversely, one study showed a decrease in the oropharyngeal volume although not statistically significant, ${ }^{15,23}$ and another three studies found no differences in the oropharyngeal volume. ${ }^{15,25-27}$ Out of five studies analyzed by Ortu et al., two did not find changes in the oropharynx volume after RME; the other three found increases, one in the retropalatal crosssectional area, one in the retropalatal plane, and one in oropharyngeal volume. ${ }^{19}$ One author stated that the improvement of airway ventilation was related to the "new" lower position of the tongue. ${ }^{15,25}$ The reduction of upper airway resistance was linked to the changes in the nasal valves, the widening of the nasopharyngeal cavity, and the increase in the total airway volume. ${ }^{17}$ Baratieri et al. noted in their study a moderate level of evidence showing that RME increases nasal cavity width and posterior nasal airway according to the quality of evidence tool assessed. ${ }^{10}$

\section{Long-term Effects}

An overall decrease in AHI results after RME treatment was described by Huynh et al $(P=0.005$ from baseline to follow-up of 6 to 12 months in one study, and $P=0.046$ from baseline to follow-up at 10 to 16 months in another study). ${ }^{7}$ Baratieri et al. evaluated the long-term effects of RME on upper airway dimensions. ${ }^{10}$ They stated an indication of the stability of the results for at least 11 months after treatment with RME, although one study concluded that there was stability up to 5 years. ${ }^{10}$

\section{Type of RME and Diagnostic Examinations}

Hyrax and Haas appliances, reported as banded or bonded, were used in the studies included in each systematic review. ${ }^{11,18}$ The activation protocol that was most commonly reported was two turns a day. ${ }^{11}$ However, the type of appliance was poorly described by some authors. Huynh et al.'s description of studies was limited; there was no information on the type of appliances used, only vague descriptions such as "fixed", "in situ", or "exsitu". 7 All the articles evaluated by Vale et al. reported the use of banded RME appliances. ${ }^{18}$ Camacho et al., Alyessary et al., Lee et al., and Ortu et al. did not mention the type of RME used in the included articles. ${ }^{9,17,19,20}$ The reported examinations used to appraise the breathing capacity were PSG, AR,,${ }^{11,20}$ and rhinomanometry. ${ }^{11,20}$ The upper airway dimensional changes were assessed with either CBCT, ${ }^{11,18,20,22,23} \mathrm{CT}^{3,20}$ or MRI. ${ }^{20}$

\section{Synthesis of Results}

Ten systematic reviews were included in this study; all of them were written in English and published between 2009 and 2019. One study was from a group from the United States, Portugal, and Italy ${ }^{9}$; one from Malaysia and Singapore ${ }^{17}$; one from Brazil ${ }^{10}$; two from Canada ${ }^{7,16}$; one from Taiwan ${ }^{20}$; one from Portugal ${ }^{18}$; one from a group from Australia, Germany, and Greece ${ }^{2}$; and two from Italy. ${ }^{15,19}$ Of the 10 systematic reviews, 3 studies focused on patients with OSA. ${ }^{7,9,18}$

The reviews were critically appraised for quality of evidence using the AMSTAR 2 tool ${ }^{14}$; the results showed only one ${ }^{2}$ systematic review scored as high quality of evidence. From the included systematic reviews, it was possible to retrieve 53 articles in total that studied upper airway changes after orthodontic treatment using RME in patients with a constricted maxilla (bilateral or unilateral crossbites). Nineteen of them reported results related to breathing capacity, 2 related to the oral cavity or the palatal volume, 29 related to the nasal volume, 11 related to nasopharynx, and 9 related to oropharynx. The mean age of the assessed patients ranged from 5.9 to 14 years.

The overall conclusion of these included systematic reviews is that an increase in the nasal cavity volume, a decrease in airway resistance, and a decrease in AHI among children in whom OSA is diagnosed are usually observed immediately after the treatment with RME. Nasopharyngeal volume and minimal cross-sectional area increases were shown with seven articles claiming an increase after RME and three claiming no change was apparent. The major uncertainty regarding the results was focused on the oropharynx, where three studies reported an increase in the oropharynx, four reported no changes, and two reported a decrease in oropharynx after RME treatment. $^{22-26,28-31}$ The relative lack of long-term followup studies has to be noted. How much of the decrease in 
airway resistance and $\mathrm{AHI}$ is only temporary?

\section{Risk of Bias Across Studies}

A large number of dissimilarities were seen across the studies. The studies differ regarding the area of the airway analyzed, which could be interesting to have results focused on just one area. ${ }^{22}$ However, the upper airway's boundaries used in the included studies in each review for times were different. The retropalatal plane described in one study was at the same anatomic boundary as the nasopharyngeal space of another included study and was the same boundary of the oropharyngeal space in another. This discrepancy leads to uncertainties among the results.

In addition, the differences in types of examinations made the comparator factor impossible. It is not possible to compare the dimensional changes found via AR to those found with CBCT. The lack of more studies evaluating the long-term effects of RME on the upper airway still should raise some degree of skepticism. The main RoB limitation within studies was the lack of a registered protocol, and sometimes the authors mentioned that there was a protocol; however, there was no registration number described. Only two studies reported a previous plan for the meta-analysis and investigation of the heterogeneity causes. ${ }^{2,9}$ Four studies did not describe the included studies in detail. $^{9,16,17,20}$

\section{DISCUSSION}

The objective of this umbrella review was to summarize the findings on the effect of the RME on the upper airway. Methodologic flaws and differences did not support a direct comparison between some results. Moreover, such superficial comparison can lead to inaccuracies, especially concerning nasopharynx, oropharynx, and retropalatal pharynx boundaries and nomenclatures, as reported by the included studies.

The increased nasal cavity volume after RME treatment seems to be consistently reported by several systematic reviews. ${ }^{2,7,10,15-17}$ Overall their results showed an increase in the nasal cavity by approximately $10 \%$ to $12 \% .^{2,15,20,32}$ Supporting articles associated these volumetric changes with a decrease in nasal resistance and some degree of AHI normalization tendency. ${ }^{7,9,18}$ The decrease ranged from $8 \%$ to $95 \% .^{9,15,16,18}$ However, caution is needed because it is not possible to automatically imply improved breathing function only by AHI changes.

In regard to nasopharynx dimensional changes, several studies have found increases in volume and/or MCA, demonstrating increases of up to $29 \%$. . $^{215,28,30,33,34}$

However, few studies have evaluated the effects of RME in the oropharynx and the results are controversial: three studies reported an increase (retropalatal plane; retropalatal airway; oropharyngeal sagittal and axial area), four studies reported no changes, and two studies reported decreases of oropharynx dimensions. ${ }^{22-26,28-31}$

In general, the heterogeneity was found to be high, ${ }^{18,21,23}$ although not all the systematic reviews performed a meta-analysis. The systematic reviews that evaluated upper airway dimensions were rated with a high level of evidence, ${ }^{2}$ moderate level of evidence, ${ }^{11}$ low level of evidence, ${ }^{18,19}$ and critically low level of evidence. ${ }^{20,22,23}$ The systematic reviews that analyzed AHI were scored with critically $\operatorname{low}^{7,21}$ and low $^{10}$ quality of evidence. Although the study by Huynh et al. was fully organized and complete, the RoB was not individually reported or discussed; for this reason, according to the AMSTAR 2 tool their rating dropped off to the critically low quality of evidence. ${ }^{7}$ An increase in the palatal volume may be related to a better repositioning of the tongue posture, increasing the airway space in the oropharynx level. ${ }^{3,35}$ The tongue might be positioned closer to the roof of the palate, displacing the tongue away from the oropharynx, possibly leading to more consistent nasal breathing. ${ }^{7}$ However, caution is needed to correlate findings in this sense because the difference in tongue position can be related to swallowing or breathing phases during the CBCT examinations in children; even when the radiology technician uses a strict protocol, tongue movement is not unlikely to occur. ${ }^{18}$

The transverse changes in the maxillary halves and consequently on the nasal walls after the maxillary expansion procedure seem to be directly related to the nasal cavity dimensional changes. ${ }^{3-6}$ Furthermore, these changes might be related to the findings on reduced nasal resistance and normalization of AHI. ${ }^{7}$ Based on linear measurements, Lagravère et al. reported transverse maxillary statistically significant changes in the nasal cavity width (intercondylar width) and inter-alveolar width. ${ }^{1}$ Concerning vertical changes, the changes in the mandibular plane in relation to the palatal plane and sella nasion plane were relatively minor $\left(1.65^{\circ}\right.$ and $1.97^{\circ}$ respectively). ${ }^{1}$ However, some studies have found no significant changes in transversal skeletal width, although changes in transversal molar and premolar width were found, suggesting dental tipping. ${ }^{1}$ Although others have supported significant transversal findings, important increases to the maxillary alveolar width were found but the clinical significance is still questionable. ${ }^{1}$ Nonsignificant anteroposterior skeletal changes were found, but significant vertical changes were confirmed in the mandibular plane angulation $(P<0.05)$. However, those findings may not be clinically significant. ${ }^{1,11}$

Regarding the tools utilized, a nocturnal PSG gives a reliable and objective assessment of nocturnal breathing capacity. ${ }^{35}$ However, because RME anatomic changes might occur at different upper airway levels, it is impossible to know to which part of the upper airway the changes are related. The AR is an interesting examination approach that provides cross-sectional area and volume of the nasal cavity and pharynx through the reflection of 
sound waves. Nasal decongestants can be used to remove short-term pathologic constriction effects and acute inflammation. ${ }^{19}$ However, it is also not possible to know which part of the upper airway has increased in regard to the RME effect. Both PSG and AR require special equipment and analysis by an ear, nose, and throat specialist.

Few studies evaluated the long-term effects of RME on upper airway dimensions ${ }^{7,10}$; one of them implied higher stability in a group of adolescents if RME was done before the pubertal peak of growth. ${ }^{16}$ The higher stability in the group treated before the peak of growth could be related to less palatal suture calcification at the time of expansion and a lower resistance against the expansion forces. ${ }^{6}$ In agreement with stability results, Pirelli et al. found the RME results to be stable after 12 years in a group of children in whom OSA was diagnosed. ${ }^{36}$ Additionally, the long-term effect is not an easy matter of debate considering the Scammon growth curve and craniofacial growth, and the various ages are going to process the long-term effects differently. In addition, several studies did not consider samples of untreated growing study patients.

During craniofacial growth, the nasopharynx volume can reach rates of up to $80 \%$ of the increase. ${ }^{37}$ Hence, not only can orthodontic treatment influence size, but lymphoid tissue growth related to the Scammon growth curve will influence the relative upper airway dimensions at the oropharyngeal and nasopharyngeal levels as well. ${ }^{38}$ Tonsil and adenoid tissues quickly increase during in younger patients, with a slower development after that, a peak before adolescence, and a decrease approaching adulthood. ${ }^{37,38}$ Therefore, it is possible that the increase in the nasopharyngeal airway is related to the spontaneous reduction of the lymphoid tissue due to age or normal craniofacial growth changes. In contrast to a previous systematic review of systematic reviews on the same RME treatment and its effects on upper airway subject, the decision was made to include studies that focused on patients with sleep-breathing disorders and also those that were performed in healthy patients. ${ }^{6}$ Because the intention was to summarize the findings in this area, and because those patients underwent RMT, the results of pharyngeal and nasal dimensions, breathing capacity, AHI, and oxygen patency are extremely valid to be analyzed. Because twodimensional imaging studies have been related to the superimposition of structures and magnification and low accuracy to visualize the upper airway, the decision was made not to include studies based on lateral twodimensional cephalometric radiographs..$^{37,39,40}$

In line with the proposal for this systematic review, more studies that measure breathing function on the oropharyngeal changes related to RME are necessary to understand the real effects of RME in the cited region of the pharynx. Although according to some authors, RME can positively influence the breathing capacity of patients with OSA. ${ }^{7,9,18}$ RME treatment is an auxiliary method ${ }^{18}$ and should be used only when orthodontically indicated.

\section{Limitations}

The authors of this umbrella review acknowledge that one included study ${ }^{22}$ was not a systematic review, but a narrative review. Hence, that review failed to provide information commonly reported in systematic reviews. Nevertheless, the decision to include this study was based on the fact that it is a relevant review addressing this topic.

Overall the value of an umbrella review greatly depends on the quality and risk of bias of the included primary studies. For this topic, several methodologic, clinical, and statistical issues were identified that would preclude stronger conclusions.

\section{Future Directions}

In line with the proposal for this systematic review, further studies with enhanced methods on the upper airway volumetric changes related to RME are needed to improve understanding of the real effects of RME on airway function. Also, future studies should analyze airway function to correlate the volumetric changes to actual breathing capacity and functional performance after maxillary expansion treatment. In addition, subjective analysis of patient's perceptions of breathing improvement after orthodontic therapy should be made.

Finally, efforts should be made to identify which phenotypic characteristics are associated with better functional breathing responses. It is becoming more clear that not all the individuals with OSA respond similarly to any given management therapy.

\section{CONCLUSION}

A significant amount of research has been published linking RME changes to an increase in nasal respiratory capability, nasal volume, and linear transverse enlargement. However, inconsistencies and disagreements among the included study results, especially the oropharyngeal dimensional changes after RME, lead to uncertainties about the effect of RME on the oropharynx region.

It is not clear that upper airway dimensional changes necessarily imply an improvement in actual breathing function. Having stated this, some studies have measured a decrease in upper airway resistance associated with the dimensional changes. If this decrease automatically implies improvements in breathing function as objectively or subjectively qualified is unknown.

Finally, any portrayed dimensional changes would be important for patients with a maxillary constriction to start with. Those cases would need to have a maxillary expansion regardless of breathing changes or not. Although according to some authors RME can positively influence 
the breathing capacity of patients with OSA, RME treatment is an auxiliary method and should be used only when orthodontically indicated. Hence, RME could be considered a positive adjunctive sleep breathing management tool for a specific subgroup of children with maxillary constriction. So far, such subgroup has not been identified.

\section{REFERENCES}

1. Lagravère M, Carey J, Heo G, Toogood R, Major P. Transverse, vertical, and anteroposterior changes from bone-anchored maxillary expansion vs traditional rapid maxillary expansion: A randomized clinical trial. Am J Orthod Dentofac Orthop. 2010;137(3):304.e1304.e12.

2. Buck LM, Dalci O, Ali Darendeliler M, Papageorgiou SN, Papadopoulou AK. Volumetric upper airway changes after rapid maxillary expansion: A systematic review and meta-analysis. Eur $J$ Orthod. 2017;39(5):463-473. doi:10.1093/ejo/cjw048

3. Taşpinar F, Uçüncü H, Bishara SE. Rapid maxillary expansion and conductive hearing loss. Angle Orthod. 2003;73:669-673.

4. Hartgerink D V., Vig PS, Orth D, Abbott DW. The effect of rapid maxillary expansion on nasal airway resistance. Am J Orthod Dentofac Orthop. 1987;92(5):381-389. doi:10.1016/08895406(87)90258-7

5. Pirelli P, Saponara M, Attanasio G. Obstructive sleep apnoea syndrome (OSAS) and rhino-tubaric dysfunction in children: therapeutic effects of RME therapy. Prog Orthod. 2005;6(1):48-61.

6. Bucci R, Montanaro D, Rongo R, Valletta R, Michelotti A, D'Antò $\mathrm{V}$. Effects of maxillary expansion on the upper airways: Evidence from systematic reviews and meta-analyses. $J$ Oral Rehabil. 2019;46(4):377-387. doi:10.1111/joor.12766

7. Huynh NT, Desplats E, Almeida FR. Orthodontics treatments for managing obstructive sleep apnea syndrome in children: A systematic review and meta-analysis. Sleep Med Rev. 2016;25:84-94. doi:10.1016/j.smrv.2015.02.002

8. Abdullatif J, Certal V, Zaghi S, et al. Maxillary expansion and maxillomandibular expansion for adult OSA: A systematic review and meta-analysis. J Craniomaxillofac Surg. 2016;44(5):574-578. doi:10.1016/j.jcms.2016.02.001

9. Camacho M, Chang ET, Song SA, et al. Rapid maxillary expansion for pediatric obstructive sleep apnea: A systematic review and metaanalysis. Laryngoscope. 2017;127(7):1712-1719. doi:10.1002/lary.26352

10. Baratieri C, Alves M, De Souza MMG, De Souza Araújo MT, Maia LC. Does rapid maxillary expansion have long-term effects on airway dimensions and breathing? Am J Orthod Dentofac Orthop. 2011;140(2):146-156. doi:10.1016/j.ajodo.2011.02.019

11. Alsufyani NA, Noga ML, Witmans M, Major PW. Upper airway imaging in sleep-disordered breathing: role of cone-beam computed tomography. Oral Radiol. 2017;33(3):161-169. doi:10.1007/s11282017-0280-1

12. Moher D, Liberati A, Tetzlaff J, Altman DG. Preferred Reporting Items for Systematic review and Meta-Analysis Protocols: The PRISMA Statement. PLoS Med. 2009;6(6):e-10.

13. Ouzzani M, Hammady H, Fedorowicz Z, Elmagarmid A. Rayyan-a web and mobile app for systematic reviews. Syst Rev. 2016;5(1):210. doi:10.1186/s13643-016-0384-4

14. Shea BJ, Reeves BC, Wells G, et al. AMSTAR 2: a critical appraisal tool for systematic reviews that include randomized or nonrandomized studies of healthcare interventions, or both. BMJ. 2017;358:j4008. doi:10.1136/bmj.j4008

15. Di Carlo G, Saccucci M, Ierardo G, et al. Rapid maxillary expansion and upper airway morphology: a systematic review on the role of cone beam computed tomography. Biomed Res Int. 2017; Article ID 54604292017:1-10. doi:10.1155/2017/5460429

16. Gordon JM, Rosenblatta M, Witmans M, et al. Rapid palatal expansion effects on nasal airway dimensions as measured by acoustic rhinometry. Angle Orthod. 2009;79(5):1000-1007. doi: $10.2319 / 082108-441.1$

17. Alyessary AS, Othman SA, Yap AUJ, Radzi Z, Rahman MT. Effects of non-surgical rapid maxillary expansion on nasal structures and breathing: A systematic review. Int Orthod. 2019;17(1):12-19. doi:10.1016/j.ortho.2019.01.001

18. Vale F, Albergaria M, Carrilho E, et al. Efficacy of rapid maxillary expansion in the treatment of obstructive sleep apnea syndrome: a systematic review with meta-analysis. J Evid Based Dent Pract. 2017;17(3):159-168.

19. Ortu E, Giannoni M, Ortu M, Gatto R, Monaco A. Oropharyngeal airway changes after rapid maxillary expansion: the state of the art. Int $J \quad$ Clin Exp Med. 2014;7(7):1632-1638. doi:10.1016/j.ajodo.2012.11.019

20. Lee W, Tu Y, Huang C, Chen R, Fu M, Fu E. Pharyngeal airway changes following maxillary expansion or protraction: A meta- analysis. Orthod Craniofac Res. 2018;21:4-11. doi:10.1111/ocr.12208

21. American Association of Orthodontics TF. White Paper: Obstructive Sleep Apnea and Orthodontics.; 2019. https://www1.aaoinfo.org/wpcontent/uploads/2019/03/sleep-apnea-white-paper-amended-March2019.pdf.

22. El H, Palomo JM. Three-dimensional evaluation of upper airway following rapid maxillary expansion: A CBCT study. Angle Orthod. 2014;84(2):265-273. doi:10.2319/012313-71.1

23. Zeng J, Gao X. A prospective CBCT study of upper airway changes after rapid maxillary expansion. Int $J$ Pediatr Otorhinolaryngol. 2013;77(11):1805-1810. doi:10.1016/j.ijporl.2013.07.028

24. Ribeiro ANC, De Paiva JB, Rino-Neto J, Illipronti-Filho E, Trivino $\mathrm{T}$, Fantini SM. Upper airway expansion after rapid maxillary expansion evaluated with cone beam computed tomography. Angle Orthod. 2012;82(3):458-463. doi:10.2319/030411-157.1

25. Iwasaki T, Saitoh I, Takemoto Y, et al. Tongue posture improvement and pharyngeal airway enlargement as secondary effects of rapid maxillary expansion: A cone-beam computed tomography study. Am $J$ Orthod Dentofac Orthop. 2013;143(2):235-245. http://dx.doi.org/10.1016/j.ajodo.2012.09.014. Accessed January 8, 2019.

26. Pangrazio-Kulbersh V, Wine P, Haughey M, Pajtas B, Kaczynski R. Cone beam computed tomography evaluation of changes in the nasomaxillary complex associated with two types of maxillary expanders. Angle Orthod. 2012;82(3):448-457. doi:10.2319/072211-464.1

27. Zhao Y, Nguyen M, Gohl E, Mah JK, Sameshima G, Enciso R. Oropharyngeal airway changes after rapid palatal expansion evaluated with cone-beam computed tomography. Am J Orthod Dentofac Orthop. 2010;137(4):S71-S78. doi:10.1016/j.ajodo.2008.08.026

28. Almuzian M, Ju X, Almukhtar A, Ayoub A, Al-Muzian L, McDonald JP. Does rapid maxillary expansion affect nasopharyngeal airway? A prospective Cone Beam Computerised Tomography (CBCT) based study. Surgeon. 2018;16(1):1-11. doi:10.1016/j.surge.2015.12.006

29. Li L, Qi S, Wang H, Ren S, Ban J. Cone-beam CT evaluation of nasomaxillary complex and upper airway following rapid maxillary expansion. Zhonghua Kou Qiang Yi Xue Za Zhi. 2015;50(7):403-407. http://www.ncbi.nlm.nih.gov/pubmed/26564743.

30. Smith T, Ghoneima A, Stewart K, et al. Three-dimensional computed tomography analysis of airway volume changes after rapid maxillary expansion. Am J Orthod Dentofac Orthop. 2012;141:618-626. doi:10.1016/j.ajodo.2011.12.017

31. Chang Y, Koenig LJ, Pruszynski JE, Bradley TG, Bosio JA, Liu D. Dimensional changes of upper airway after rapid maxillary expansion: A prospective cone-beam computed tomography study. Am J Orthod Dentofac Orthop. 2013;143(4):462-470. 


\section{doi:10.1016/j.ajodo.2012.11.019}

32. Bicakci AA, Agar U, Sökücü O, Babacan H, Doruk C. Nasal airway changes due to rapid maxillary expansion timing. Angle Orthod. 2005;75(1):1-6. doi:10.1043/00033219(2005)075<0001:NACDTR>2.0.CO;2

33. Izuka EN, Feres MFN, Pignatari SSN. Immediate impact of rapid maxillary expansion on upper airway dimensions and on the quality of life of mouth breathers. Dental Press J Orthod. 2015;20(3):43-49. doi:10.1590/2176-9451.20.3.043-049.oar

34. Tecco S, Tetè S, Perillo L, Chimenti C, Festa F. Maxillary arch width changes during orthodontic treatment with fixed self-ligating and traditional straight-wire appliances. World J Orthod. 2009;10(4):290294. http://www.ncbi.nlm.nih.gov/pubmed/20072744. Accessed February 18, 2019.

35. Perlis M, Lichstein KI. Treating Sleep Disorders: Principles and Practice of Behavioral Sleep Medicine. Hoboken, New Jersey: Wiley, 2003

36. Pirelli P, Saponara M, Guilleminault C. Rapid maxillary expansion (RME) for pediatric obstructive sleep apnea: a 12-year follow-up. Sleep Med. 2015;16(8):933-935. doi:10.1016/j.sleep.2015.04.012

37. Kapila SD. Cone Beam Computed Tomography in Orthodontics: Indications, Insights, and Innovations. Ames, Iowa: WileyBlackwell; 2014. doi:10.1002/9781118674888

38. Pirelli P, Saponara M, Guilleminault C. Rapid maxillary expansion in children with obstructive sleep apnea syndrome. Sleep. 2004;27(4):761-766.

39. Rossini G, Cavallini C, Cassetta M, Barbato E. 3D cephalometric analysis obtained from computed tomography. Review of the literature. Ann Stomatol (Roma). 2011;2(3-4):31-39. http://www.ncbi.nlm.nih.gov/pubmed/22545187. Accessed March 23, 2019.

40. Lenza MG, de O Lenza MM, Dalstra M, Melsen B, Cattaneo PM. An analysis of different approaches to the assessment of upper airway morphology: a CBCT study. Orthod Craniofac Res. 2010;13(2):96105. doi:10.1111/j.1601-6343.2010.01482.x

\section{SUBMISSION \& CORRESPONDENCE INFORMATION}

\section{Submitted for publication January 22, 2020 \\ Submitted in final revised form May 18, 2020 \\ Accepted for publication May 29, 2020}

Address correspondence to: Dr. Silvia GianoniCapenakas, School of Dentistry Faculty of Medicine and Dentistry, 5-488 Edmonton Clinic Health Academy, 11405-87 Avenue NW, University of Alberta, Edmonton, AB, Canada T6G 1C9; Phone: (587) 594 9947; Email: capenaka@ualberta.ca

\section{DISCLOSURE STATEMENT}

The authors have no conflicts of interest to disclose. 
TABLES AND FIGURES

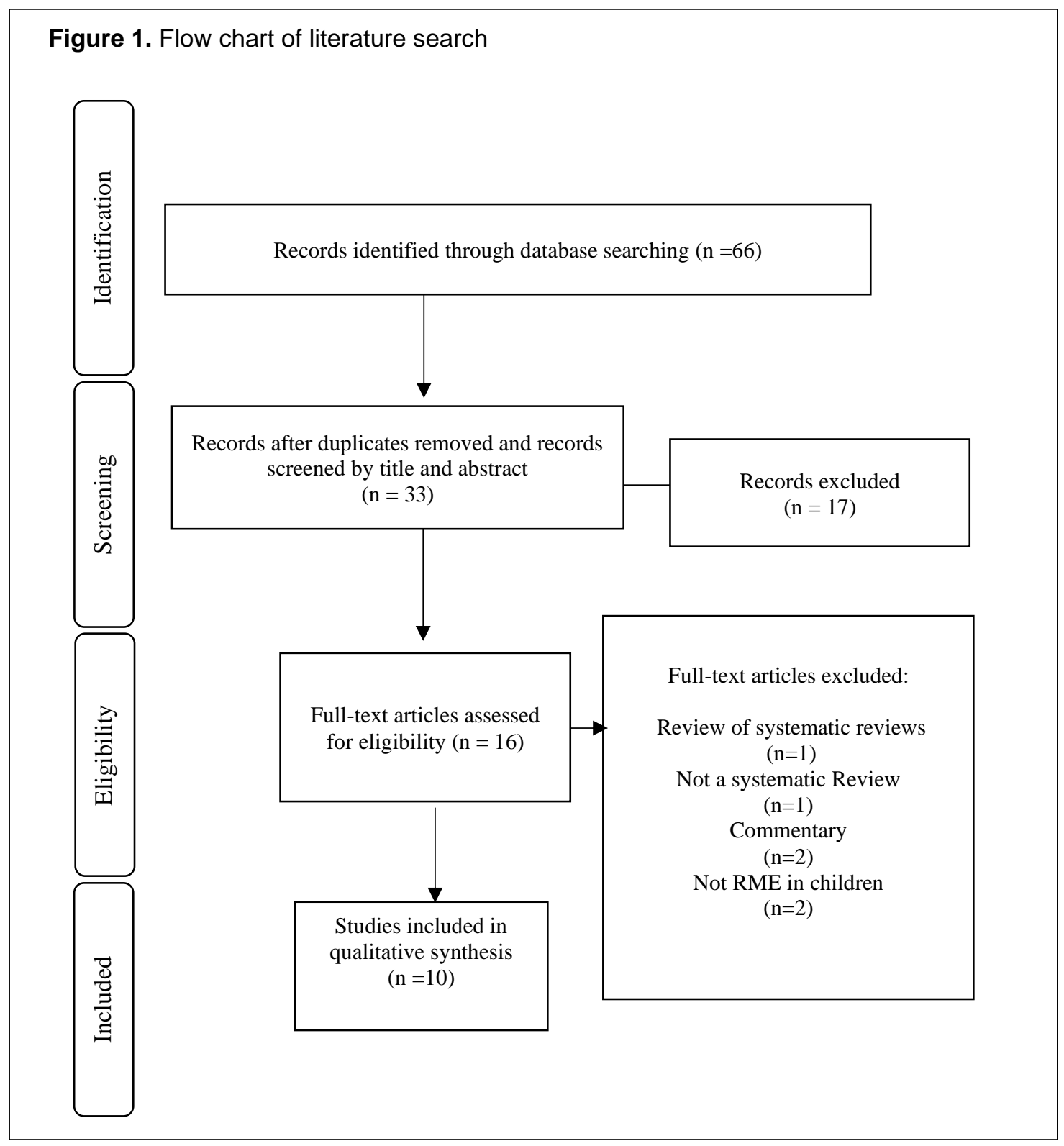


Table 1. Main Outcomes of Included Studies

\begin{tabular}{|c|c|c|c|c|c|}
\hline $\begin{array}{l}\text { Author, Country, } \\
\text { Year }\end{array}$ & $\begin{array}{l}\text { Type of } \\
\text { appliance }\end{array}$ & $\begin{array}{l}\text { Portion of } \\
\text { Airway }\end{array}$ & Type of evaluation & Test or Exam & Main results \\
\hline $\begin{array}{l}\text { Camacho M. et } \\
\text { al }^{9} 2016 \\
\text { USA }\end{array}$ & RME & $\begin{array}{l}\text { Breathing } \\
\text { capacity and } \\
\text { related } \\
\text { outcomes }\end{array}$ & $\begin{array}{l}\text { AHI; Lowest Oxygen } \\
\text { saturation; Oxygen } \\
\text { desaturation index; } \\
\text { mean oxygen } \\
\text { saturation }\end{array}$ & PSG & $\begin{array}{l}\text { AHI decreased; RME could be } \\
\text { considered for primary treatment } \\
\text { in OSA patients with the } \\
\text { constricted maxilla and small } \\
\text { tonsils. }\end{array}$ \\
\hline $\begin{array}{l}\text { Alyessary A. et } \\
\text { al }^{17} 2019 \\
\text { Malaysia, } \\
\text { Singapore, Iraq }\end{array}$ & RME & $\begin{array}{l}\text { Breathing } \\
\text { capacity and } \\
\text { upper airway } \\
\text { structures }\end{array}$ & $\begin{array}{l}\text { Nasal cavity, } \\
\text { nasopharyngeal and } \\
\text { total airway volume }\end{array}$ & $\begin{array}{l}\text { Rhinomanometry } \\
\text {, CBCT, CT, } \\
\text { MRI, CFD }\end{array}$ & $\begin{array}{l}\text { Increase in the nasal cavity width, } \\
\text { decrease in airway resistance }\end{array}$ \\
\hline $\begin{array}{l}\text { Baratieri C et al } \\
2011 \\
\text { Brazil }\end{array}$ & $\begin{array}{l}\text { RME: Bonded } \\
\text { expander; } \\
\text { Hyrax; R.E.P- } \\
\text { Dentaurum } \\
\text { Italia s.r.l.; } \\
\text { Haas. }\end{array}$ & $\begin{array}{l}\text { Breathing } \\
\text { capacity, nasal } \\
\text { cavity, } \\
\text { nasopharynx } \\
\text { and Oropharynx }\end{array}$ & $\begin{array}{l}\text { Nasal cavity width, } \\
\text { nasopharynx and } \\
\text { oropharynx volume } \\
\text { and/or cross-sectional } \\
\text { area }\end{array}$ & $\begin{array}{l}\text { Rhinomanometry } \\
\text {, AR, CT, } \\
\text { CBCT, } \\
\text { Posteroanterior } \\
\text { or Lateral } \\
\text { Radiographs }\end{array}$ & $\begin{array}{l}\text { Nasal cavity width increases, } \\
\text { reduction on nasal resistance and } \\
\text { increase in total nasal flow, } \\
\text { increases in minimal cross- } \\
\text { sectional area and nasal cavity } \\
\text { volume. }\end{array}$ \\
\hline $\begin{array}{l}\text { Di Carlo et al }{ }^{15} \\
2017 \\
\text { Italy }\end{array}$ & $\begin{array}{l}\text { RME: Haas, } \\
\text { Hyrax, } \\
\text { McNamara } \\
\text { expander, }\end{array}$ & $\begin{array}{l}\text { Airway linear } \\
\text { and volumetric } \\
\text { changes }\end{array}$ & $\begin{array}{l}\text { Linear transversal } \\
\text { and volumetric } \\
\text { changes in } \\
\text { nasopharyngeal } \\
\text { airway }\end{array}$ & CBCT & $\begin{array}{l}\text { Nasal width increase, lower nasal } \\
\text { volume increase, oropharynx } \\
\text { either decrease in one study and } \\
\text { increase in another study, } \\
\text { Nasopharyngeal volume and } \\
\text { cross-sectional area increase, } \\
\text { retropalatal oropharyngeal } \\
\text { volume increase }\end{array}$ \\
\hline $\begin{array}{l}\text { Huynh et al }{ }^{7} \\
2014 \\
\text { Canada }\end{array}$ & Not reported & $\begin{array}{l}\text { Breathing } \\
\text { capacity }\end{array}$ & $\mathrm{AHI}$ & PSG & $\begin{array}{l}\text { AHI decrease with a follow up of } \\
6 \text { and } 16 \text { months }\end{array}$ \\
\hline $\begin{array}{l}\text { Buck LM et al }{ }^{2} \\
2017 \\
\text { Australia, } \\
\text { Germany, and } \\
\text { Greece }\end{array}$ & $\begin{array}{l}\text { RME: banded } \\
\text { or bonded. } \\
\text { Hyrax or Haas }\end{array}$ & $\begin{array}{l}\text { Volumetric } \\
\text { changes in the } \\
\text { upper airway }\end{array}$ & $\begin{array}{l}\text { Nasal cavity, } \\
\text { maxillary sinus, } \\
\text { nasopharyngeal, } \\
\text { oropharyngeal, } \\
\text { hypopharyngeal and } \\
\text { palatal volume. }\end{array}$ & AR, CBCT, CT & $\begin{array}{l}\text { Increase in total airway volume. } \\
\text { Increase in nasal volume, } \\
\text { velopharynx, nasopharynx, } \\
\text { oropharynx, and hypopharynx }\end{array}$ \\
\hline $\begin{array}{l}\text { Gordon et al }{ }^{16} \\
2009 \\
\text { Canada }\end{array}$ & $\begin{array}{l}\text { Banded or } \\
\text { bonded. Hyrax, } \\
\text { Haas or } \\
\text { modified } \\
\text { Biederman }\end{array}$ & Nasal airway & MCA and volume & AR & $\begin{array}{l}\text { Increase in nasal volume, change } \\
\text { in the mode of breathing from } \\
\text { oral to nasal }\end{array}$ \\
\hline $\begin{array}{l}\text { Lee et al } \\
2017^{20} \\
\text { Taiwan }\end{array}$ & $\begin{array}{l}\text { No information } \\
\text { on the type of } \\
\text { RME }\end{array}$ & Pharynx & Volume & CBCT & $\begin{array}{l}\text { Increase in the nasal passage } \\
\text { airway volume. No oropharyngeal } \\
\text { volume changes founded }\end{array}$ \\
\hline $\begin{array}{l}\text { Vale et al } \\
2017^{18} \\
\text { Portugal }\end{array}$ & Banded RME & $\begin{array}{l}\text { Breathing } \\
\text { capacity }\end{array}$ & $\mathrm{AHI}$ & PSG & Improvement in $\mathrm{AHI}$ \\
\hline $\begin{array}{l}\text { Ortu et al } \\
2014^{19} \\
\text { Italy }\end{array}$ & $\begin{array}{l}\text { Banded or } \\
\text { bonded. }\end{array}$ & $\begin{array}{l}\text { Oropharyngeal } \\
\text { airway }\end{array}$ & $\begin{array}{l}\text { Retropalatal and } \\
\text { retroglossal volume }\end{array}$ & $\mathrm{CBCT}$ & $\begin{array}{l}\text { Oropharyngeal volume increase, } \\
\text { retropalatal cross-sectional area } \\
\text { increase, however, one study } \\
\text { found no changes in the } \\
\text { oropharyngeal airway }\end{array}$ \\
\hline
\end{tabular}


Table 2. AMSTAR 2 critical appraisal tool for quality assessment.

\begin{tabular}{|c|c|c|c|c|c|c|c|c|c|c|}
\hline \multicolumn{11}{|l|}{ AMSTAR2 } \\
\hline Questions & 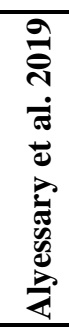 & 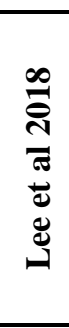 & 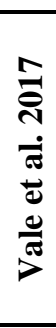 & 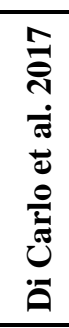 & 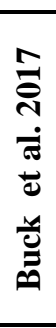 & 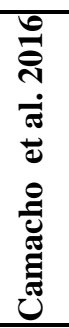 & 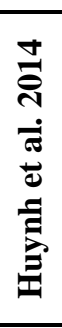 & 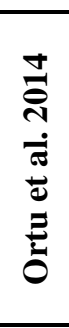 & 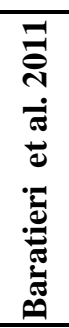 & 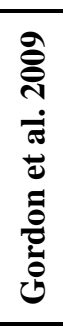 \\
\hline $\begin{array}{l}\text { 1. Did the research questions and inclusion criteria for the review } \\
\text { include the components of PICO? }\end{array}$ & Y & Y & Y & $\mathrm{Y}$ & Y & $\mathrm{Y}$ & Y & $\mathrm{Y}$ & $\mathrm{Y}$ & Y \\
\hline $\begin{array}{l}\text { 2. Did the report of the review contain an explicit statement that the } \\
\text { review methods were established prior to the conduct of the review } \\
\text { and did the report justify any significant deviations from the protocol? }\end{array}$ & $\mathrm{N}$ & $\mathrm{N}$ & $\mathrm{N}$ & PY & $\mathrm{Y}$ & PY & PY & $\mathrm{N}$ & PY & PY \\
\hline $\begin{array}{l}\text { 3. Did the review authors explain their selection of the study designs } \\
\text { for inclusion in the review? }\end{array}$ & $\mathrm{N}$ & $\mathrm{N}$ & $\mathrm{N}$ & $\mathrm{N}$ & Y & $\mathrm{N}$ & Y & $\mathrm{N}$ & Y & $\mathrm{N}$ \\
\hline $\begin{array}{l}\text { 4. Did the review authors use a comprehensive literature search } \\
\text { strategy? }\end{array}$ & PY & PY & PY & PY & Y & PY & Y & $\mathrm{Y}$ & PY & PY \\
\hline 5. Did the review authors perform study selection in duplicate? & $\mathrm{N}$ & Y & Y & $\mathrm{Y}$ & Y & Y & Y & Y & Y & $\mathrm{Y}$ \\
\hline 6. Did the review authors perform data extraction in duplicate? & $\mathrm{N}$ & Y & Y & $\mathrm{N}$ & Y & Y & $\mathrm{Y}$ & $\mathrm{N}$ & Y & $\mathrm{N}$ \\
\hline $\begin{array}{l}\text { 7. Did the review authors provide a list of excluded studies and justify } \\
\text { the exclusions? }\end{array}$ & $\mathrm{N}$ & $\mathrm{N}$ & Y & $\mathrm{N}$ & Y & $\mathrm{N}$ & $\mathrm{Y}$ & $\mathrm{N}$ & Y & $\mathrm{Y}$ \\
\hline $\begin{array}{l}\text { 8. Did the review authors describe the included studies in adequate } \\
\text { detail? }\end{array}$ & $\mathrm{N}$ & PY & Y & $\mathrm{Y}$ & Y & PY & $\mathrm{Y}$ & $\mathrm{Y}$ & $\mathrm{Y}$ & PY \\
\hline $\begin{array}{l}\text { 9. Did the review authors use a satisfactory technique for assessing the } \\
\text { risk of bias (RoB) in individual studies that were included in the } \\
\text { review? }\end{array}$ & $\mathrm{N}$ & Y & PY & $\mathrm{Y}$ & Y & Y & $\mathrm{N}$ & $\mathrm{N}$ & Y & Y \\
\hline $\begin{array}{l}\text { 10. Did the review authors report on the sources of funding for the } \\
\text { studies included in the review? }\end{array}$ & $\mathrm{N}$ & $\mathrm{N}$ & $\mathrm{N}$ & $\mathrm{N}$ & $\mathrm{N}$ & $\mathrm{N}$ & $\mathrm{N}$ & $\mathrm{N}$ & $\mathrm{N}$ & $\mathrm{N}$ \\
\hline $\begin{array}{l}\text { 11. If meta-analysis was performed did the review authors use } \\
\text { appropriate methods for statistical combination of results? }\end{array}$ & NA & Y & $\mathrm{Y}$ & NA & Y & Y & $\mathrm{Y}$ & NA & NA & NA \\
\hline $\begin{array}{l}\text { 12. If meta-analysis was performed, did the review authors assess the } \\
\text { potential impact of RoB in individual studies on the results of the } \\
\text { meta-analysis or other evidence synthesis? }\end{array}$ & NA & $\mathrm{N}$ & $\mathrm{N}$ & NA & Y & Y & $\mathrm{N}$ & NA & NA & NA \\
\hline $\begin{array}{l}\text { 13. Did the review authors account for RoB in individual studies when } \\
\text { interpreting/ discussing the results of the review? }\end{array}$ & $\mathrm{N}$ & $\mathrm{N}$ & $\mathrm{N}$ & $\mathrm{Y}$ & Y & Y & $\mathrm{N}$ & $\mathrm{N}$ & Y & $\mathrm{N}$ \\
\hline $\begin{array}{l}\text { 14. Did the review authors provide a satisfactory explanation for, and } \\
\text { discussion of, any heterogeneity observed in the results of the review? }\end{array}$ & $\mathrm{N}$ & Y & Y & $\mathrm{N}$ & Y & Y & $\mathrm{Y}$ & $\mathrm{N}$ & $\mathrm{N}$ & $\mathrm{N}$ \\
\hline $\begin{array}{l}\text { 15. If they performed quantitative synthesis did the review authors } \\
\text { carry out an adequate investigation of publication bias (small study } \\
\text { bias) and discuss its likely impact on the results of the review? }\end{array}$ & NA & $\mathrm{N}$ & $\mathrm{N}$ & NA & Y & Y & $\mathrm{N}$ & NA & NA & NA \\
\hline $\begin{array}{l}\text { 16. Did the review authors report any potential sources of conflict of } \\
\text { interest, including any funding they received for conducting the } \\
\text { review? }\end{array}$ & $\mathrm{Y}$ & $\mathrm{N}$ & $\mathrm{N}$ & $\mathrm{Y}$ & Y & Y & Y & Y & Y & $\mathrm{N}$ \\
\hline Result & CL & CL & CL & $\mathrm{L}$ & $\mathrm{H}$ & $\mathrm{L}$ & CL & CL & M & $\mathrm{L}$ \\
\hline
\end{tabular}

Y-yes, N- no, PY- partial yes, NA - not applicable, CL - critically low, L - low, M - moderate, H - high 


\section{APPENDICES}

Appendix 1. Studies included in the systematic reviews

\begin{tabular}{|c|c|c|}
\hline $\begin{array}{l}\text { Authors } \\
\text { Year }\end{array}$ & $\begin{array}{l}\text { Mean age } \\
\text { Sample size }\end{array}$ & Effects of RME on airway \\
\hline Monini et al. 2009 & $\begin{array}{l}7.8 \text { y } \\
\mathrm{N}=65\end{array}$ & $\begin{array}{c}\text { There was an improvement of nasal respiration in children via a widening } \\
\text { effect on the nasopharyngeal cavity. }\end{array}$ \\
\hline Aloufi et al. 2012 & $\begin{array}{l}14.2 \mathrm{y} \\
\mathrm{N}=30\end{array}$ & $\begin{array}{c}\text { Positive effect on the upper pharyngeal airway. RME did not significantly } \\
\text { improve the mode of breathing. }\end{array}$ \\
\hline Iwasaki et al. 2012 & $\begin{array}{l}10.2 y \\
N=23\end{array}$ & $\begin{array}{c}\text { Improvement of nasal airway ventilation by rapid maxillary the expansion } \\
\text { was detected by computational fluid dynamics }\end{array}$ \\
\hline Iwasaki et al. 2014 & $\begin{array}{l}9.7 \mathrm{y} \\
\mathrm{N}=25\end{array}$ & $\begin{array}{c}\text { The nasal airway ventilation conditions were improved and constriction of } \\
\text { the pharyngeal airway less likely after RME }\end{array}$ \\
\hline Caprioglio et al. 2014 & $\begin{array}{r}7.1 \mathrm{y} \\
\mathrm{N}=14\end{array}$ & Increases in total airway volume \\
\hline Fastuca et al. 2015 & $\begin{array}{l}7.5 \mathrm{y} \\
\mathrm{N}=15\end{array}$ & $\begin{array}{c}\text { The upper, middle, and lower airway volumes, and oxygen saturation } \\
\text { significant increased, } 71 \% \text { of AHI decrease }\end{array}$ \\
\hline Izuka et al.2015 & $\begin{array}{l}10.5 \mathrm{y} \\
\mathrm{N}=25\end{array}$ & $\begin{array}{l}\text { Significant gain in the airway volume of the nasopharynx and nasal cavity, } \\
\text { and also in the anterior and posterior widths of the nasal floor }\end{array}$ \\
\hline Compadretti et al. 2006 & $\begin{array}{c}14 \mathrm{y} \\
\mathrm{N}=27\end{array}$ & $\begin{array}{l}\text { Increase in nasal width. Decreased nasal airway resistance and increased total } \\
\text { minimal cross-sectional area using AR }\end{array}$ \\
\hline Enoki et al. 2006 & $\begin{array}{l}8.5 \mathrm{y} \\
\mathrm{N}=29\end{array}$ & $\begin{array}{c}\text { Decreased nasal airway resistance but no significant change in minimal } \\
\text { cross-sectional-area }\end{array}$ \\
\hline Doruk et al. 2007 & $\begin{array}{c}13 \mathrm{y} \\
\mathrm{N}=10\end{array}$ & Increased nasal cavity volume evaluated with $\mathrm{CT}$ and AR \\
\hline Palaisa et al. 2007 & $\begin{array}{l}11.5 \mathrm{y} \\
\mathrm{N}=19\end{array}$ & $\begin{array}{c}10 \% \text { increase in the nasal area and nasal volume } \\
\text { using CT }\end{array}$ \\
\hline Oliveira et al. 2008 & $\begin{array}{c}13 \mathrm{y} \\
\mathrm{N}=38\end{array}$ & $\begin{array}{c}\text { A mean reduction of nasal airway resistance; and mean increases in total } \\
\text { nasal volume analyzed via AR without decongestant and model scanning and } \\
\text { nasal valve area }\end{array}$ \\
\hline $\begin{array}{l}\text { Haralambidis et al. } \\
\qquad 2009\end{array}$ & $\begin{array}{l}14.5 \mathrm{y} \\
\mathrm{N}=24\end{array}$ & $\begin{array}{l}\text { A significant average increase of } 11.3 \% \text { in nasal volume. Sex, growth and the } \\
\text { skeletal relationship did not influence measurements }\end{array}$ \\
\hline Matsumoto et al. 2010 & $\begin{array}{l}8.5 \mathrm{y} \\
\mathrm{N}=27\end{array}$ & $\begin{array}{l}\text { RME significantly increased nasal and maxillary width, but the nasal mucosal } \\
\text { effects were subtler and not stable }\end{array}$ \\
\hline Görgülü et al. 2011 & $\begin{array}{l}13.8 \mathrm{y} \\
\mathrm{N}=15\end{array}$ & $12.1 \%$ increase was measured in nasal cavity volume evaluated through CT \\
\hline Langer et al. 2011 & $\begin{array}{l}8.5 \mathrm{Y} \\
\mathrm{N}=25\end{array}$ & $\begin{array}{l}\text { RME does not influence on the nasopharyngeal area or nasal airway } \\
\text { resistance in long-term evaluation }\end{array}$ \\
\hline
\end{tabular}




\begin{tabular}{|c|c|c|}
\hline Cordasco et al. 2012 & $\begin{array}{l}9.7 \text { y } \\
\mathrm{N}=8\end{array}$ & $\begin{array}{l}\text { Significant enlarge the dimension of the nasal cavity, and the increment is } \\
\text { larger in the lower part of the nose and equally distributed between the } \\
\text { anterior and the posterior part of the nasal cavity. }\end{array}$ \\
\hline Smith et al. 2012 & $\begin{array}{l}11.5 \text { y } \\
\mathrm{N}=20\end{array}$ & $\begin{array}{c}\text { Significant increases in nasal cavity volume and nasopharynx volume. No } \\
\text { increase found in the oropharynx, hypopharynx, and maxillary sinuses. CT } \\
\text { was used to evaluate the airway }\end{array}$ \\
\hline $\begin{array}{l}\text { Itikawa et al. } \\
\quad 2012\end{array}$ & $\begin{array}{l}8.5 \mathrm{Y} \\
\mathrm{N}=29\end{array}$ & $\begin{array}{l}\text { No effect on nasal resistance since the nasal bony expansion is followed by a } \\
\text { mucosal compensation }\end{array}$ \\
\hline Chang et al. 2013 & $\begin{array}{l}12.9 \mathrm{y} \\
\mathrm{N}=14\end{array}$ & $\begin{array}{l}\text { No changes in retropalatal and retroglossal and total volumes. Only the cross- } \\
\text { sectional area of the upper airway at the posterior nasal spine to basion level } \\
\text { significantly showed a moderate increase after RME }\end{array}$ \\
\hline Pirelli et al. 2015 & $\begin{array}{r}8.6 \mathrm{y} \\
\mathrm{N}=23\end{array}$ & 95\% AHI decrease, $16 \%$ improvement in LSAT \\
\hline Taddei et al. 2015 & $\begin{array}{l}8.9 \mathrm{y} \\
\mathrm{N}=30 \\
\end{array}$ & 7.7\% AHI decrease \\
\hline Villa et al. 2015 & $\begin{array}{l}6.2 \mathrm{y} \\
\mathrm{N}=21\end{array}$ & $51 \%$ Decrease in AHI \\
\hline Hosselet et al. 2010 & $\begin{array}{c}12 \mathrm{y} \\
\mathrm{N}=10\end{array}$ & $55 \%$ AHI decrease \\
\hline Villa et al. 2014 & $\begin{array}{l}6.6 \mathrm{y} \\
\mathrm{N}=22\end{array}$ & $52 \%$ AHI decrease \\
\hline Miano et al. 2009 & $\begin{array}{l}6.4 \text { y } \\
\mathrm{N}=9\end{array}$ & $69 \%$ AHI decrease \\
\hline Villa et al. 2007 & $\begin{array}{l}6.9 \mathrm{y} \\
\mathrm{N}=14\end{array}$ & $74 \%$ AHI decrease \\
\hline Marino et al. 2012 & $\begin{array}{l}5.9 \mathrm{y} \\
\mathrm{N}=15\end{array}$ & $24 \%$ AHI decrease \\
\hline Pirelli et al. 2012 & $\begin{array}{c}7 y \\
N=40\end{array}$ & $55 \%$ AHI decrease, $11 \%$ LSAT improvement \\
\hline Villa et al. 2011 & $\begin{array}{r}6.6 \mathrm{y} \\
\mathrm{N}=10 \\
\end{array}$ & $63 \%$ AHI decrease, $2 \%$ LSAT improvement \\
\hline Pirelli et al. 2010 & $\begin{array}{l}8.7 \text { y } \\
\mathrm{N}=60\end{array}$ & $95 \%$ AHI decrease \\
\hline Cameron et al. 2002 & $\begin{array}{l}11.8 \mathrm{y} \\
\mathrm{N}=42\end{array}$ & Increase in nasal width. \\
\hline Baccetti et al. 2001 & $\begin{array}{c}12 \mathrm{y} \\
\mathrm{N}=42 \\
\end{array}$ & Increase in nasal cavity width. \\
\hline Zhao et al. 2010 & $\begin{array}{l}12.8 \mathrm{y} \\
\mathrm{N}=24\end{array}$ & $\begin{array}{l}\text { Retropalatal differences found in oropharyngeal volume when comparing } \\
\text { subjects with narrowed maxilla with subjects without narrowed maxilla }\end{array}$ \\
\hline Christie et al. 2010 & $\begin{array}{l}9.9 \mathrm{y} \\
\mathrm{N}=24\end{array}$ & Increases on nasal width \\
\hline Zeng and Gao 2013 & $\begin{array}{l}12.7 \text { y } \\
\mathrm{N}=16\end{array}$ & $\begin{array}{c}\text { Statistically significant nasal cavity width and volume increase, and } \\
\text { Oropharyngeal decrease using CBCT }\end{array}$ \\
\hline Ribeiro et al. 2012 & $\begin{array}{l}7.5 \mathrm{y} \\
\mathrm{N}=15\end{array}$ & $\begin{array}{l}\text { Increase in the nasal cavity and oropharyngeal median sagittal area }(\mathrm{p}=0.01) \\
\text { and lower axial area }(\mathrm{p}=0.04) \text { after RME. No change in nasopharynx volume. }\end{array}$ \\
\hline
\end{tabular}




\begin{tabular}{|c|c|c|}
\hline $\begin{array}{l}\text { Pangrazio-Kulbersh et al. } \\
\qquad 2012\end{array}$ & $\begin{array}{c}13 \text { y } \\
\mathrm{N}=23\end{array}$ & $\begin{array}{l}\text { Increase in the nasal cavity, and sinus volume, but no change in posterior } \\
\text { airway volume using CBCT }\end{array}$ \\
\hline Baratieri et al. 2014 & $\begin{array}{c}9 y \\
\mathrm{~N}=30\end{array}$ & Increase in nasal cavity width. \\
\hline Pirelli et al. 2004 & $\begin{array}{l}8.6 \text { y } \\
\mathrm{N}=31\end{array}$ & Changes in AHI, Arterial oxygen saturation; sleep quality \\
\hline Guilleminault et al. 2011 & $\begin{array}{l}6.5 \mathrm{y} \\
\mathrm{N}=31\end{array}$ & Changes in AHI, Arterial oxygen saturation; Respiratory disturbance index \\
\hline Almuzian et al. 2018 & $\begin{array}{l}12.6 \mathrm{y} \\
\mathrm{N}=17\end{array}$ & $\begin{array}{c}\text { Statistically significant increase in nasopharynx volume and retropalatal } \\
\text { oropharynx using CBCT }\end{array}$ \\
\hline Azaredo 2014 & $\begin{array}{l}10.7 \mathrm{y} \\
\mathrm{N}=31\end{array}$ & No statistically significant changes in total airway volume \\
\hline Babacan et al. 2006 & $\begin{array}{l}12.3 \text { y } \\
\mathrm{N}=10\end{array}$ & $\begin{array}{l}\text { Statistically significant increase in the nasal cavity volume of about } \\
12.5 \% \text { evaluated through AR without decongestant }\end{array}$ \\
\hline Cappelletti et al. 2008 & $\begin{array}{c}9 y \\
\mathrm{~N}=70\end{array}$ & $\begin{array}{l}\text { Statistically significant increase in nasal cavity evaluated through AR with a } \\
\text { decongestant }\end{array}$ \\
\hline Darsey et al. 2012 & $\begin{array}{l}13.8 \mathrm{y} \\
\mathrm{N}=30\end{array}$ & No changes in the maxillary sinuses \\
\hline Kabalan et al. 2015 & $\begin{array}{c}14 \mathrm{y} \\
\mathrm{N}=81\end{array}$ & No significant changes in the nasal cavity after RME evaluated with AR \\
\hline Li et al. 2015 & $\begin{array}{l}12.1 \mathrm{y} \\
\mathrm{N}=35\end{array}$ & $\begin{array}{c}29.9 \% \text { Increase in the nasopharyngeal volume evaluated with CBCT. No } \\
\text { changes found in the oropharynx }\end{array}$ \\
\hline Manini et al. 2007 & $\begin{array}{l}7.5 \mathrm{y} \\
\mathrm{N}=30\end{array}$ & Increase in the palatal volume evaluated with Photogrammetry \\
\hline Sokucu et al. 2010 & $\begin{array}{l}12.4 \mathrm{y} \\
\mathrm{N}=30\end{array}$ & $\begin{array}{l}\text { Increase in nasal cavity volume evaluated with AR with and without } \\
\text { decongestant }\end{array}$ \\
\hline Bicakci et al. 2005 & $\begin{array}{l}12.5 \mathrm{y} \\
\mathrm{N}=58\end{array}$ & $\begin{array}{l}\text { Increase in the nasal minimal cross-sectional area. However, a decrease was } \\
\text { seen after the retention phase }\end{array}$ \\
\hline Iwasaki et al. 2013 & $\begin{array}{l}9.82 \mathrm{y} \\
\mathrm{N}=48\end{array}$ & Decreased intraoral airway volume, and increase the pharyngeal volume \\
\hline El et al. 2014 & $\begin{array}{c}14 \text { y } \\
N=70\end{array}$ & No significant change in oropharyngeal volume. \\
\hline
\end{tabular}

